\title{
Effects of Anogeissus leiocarpus on Haematological Parameters of Mice Infected With Plasmodium berghei
}

\author{
Mojisola Christianah Cyril-Olutayo ${ }^{1}$, Akhere A. Omonkhua ${ }^{2} \&$ Olusegun M. Akanbi ${ }^{3}$ \\ ${ }^{1}$ Drug Research and Production Unit, Faculty of Pharmacy, Obafemi Awolowo University, Ile-Ife, Osun State, \\ Nigeria \\ 2 Department of Medical Biochemistry, School of Basic Medical Sciences,College of Medical Sciences, \\ University of Benin, Benin City, Edo State, Nigeria \\ ${ }^{3}$ Department of Enviromental Biology and Fisheries, Adekunle Ajasin University, Akungba Akoko, Ondo State, \\ Nigeria \\ Correspondence: Mojisola Christianah Cyril-Olutayo, Drug Research and Production Unit, Faculty of Pharmacy, \\ Obafemi Awolowo University, Ile Ife, Osun State, Nigeria. Tel: 234-803-3979-361. E-mail: \\ mojiogunyemi@yahoo.com
}

Received: October 8, 2012 Accepted: February 25, 2013 Online Published: March 10, 2013

doi:10.5539/jps.v2n2p13

URL: http://dx.doi.org/10.5539/jps.v2n2p13

\begin{abstract}
Haematological parameters are frequently used to support the diagnosis of several diseases including malaria. Anogeissus leiocapus is used traditionally to treat malaria and has been shown to possess profound antimalarial activities in Plasmodium berghei infected mice. This study evaluated the effects of the methanolic extracts of $A$. leiocarpus on the haematological status of $P$. berghei-infected mice. Twenty albino mice were inoculated intra-peritoneally with $P$. berghei while 5 others were left uninfected to serve as control, (Group A). Group B, negative control, received distilled water. Group C (positive control) was treated with artesunate at $5 \mathrm{mg} / \mathrm{kg}$ body weight while $A$. leiocarpus extract was orally administered at 100 and $200 \mathrm{mg} / \mathrm{kg}$ body weight for 4 days to Groups $\mathrm{D}$ and $\mathrm{E}$ respectively. On the fifth day of treatment, haematological parameters (red blood cell (RBC), white blood cell (WBC) and platelet counts; packed cell volume (PCV), haemoglobin ( $\mathrm{Hb})$ concentration and differential leukocyte count) were assessed using standard methods. A. leiocarpus at $100 \mathrm{mg} / \mathrm{kg}$ and $200 \mathrm{mg} / \mathrm{kg}$ body weight increased the haemoglobin, RBC and PCV levels of treated P. Berghei infected mice compared to negative control. Lymphocyte levels of these same groups significantly $(\mathrm{p}<0.05)$ increased while neutrophil level reduced. Our findings show that $A$. leiocarpus has anti-anaemic properties.
\end{abstract}

Keywords: haematology, Anogeissus leiocarpus, anaemia, Plasmodium berghei

\section{Introduction}

Malaria, which is widespread in tropical and subtropical regions, infects over 500 million people in a year; it kills between one and three million, most of whom are children in Sub-Saharan Africa (Snow, Guerra, Noor, Myint, \& Hay, 2005). Some degree of anaemia is linked to most malarial infections. The seriousness of this anaemia depends on the patient peculiarity as well as parasite features such as species and drug-resistance phenotype (Lamikanra, Brown, \& Potocnik 2007). Severe injury and death may arise from malarial anaemia particularly in children and pregnant women infected with Plasmodium falciparum (Menendez, Fleming, \& Alonso, 2000). In P. falciparum infection, several haematological changes such as anaemia, thrombocytopenia and leukocytosis have been reported (Fleming, 1981). For most of its life cycle, the malaria parasite is shielded from the body's immune system since it resides in the liver and blood cells, which are relatively invisible to immune surveillance (Chen, Schlichtherle, \& Wahlgren, 2000). Cerebral malaria occurs when sequestrated infected red blood cells breaches the blood brain barrier, a situation that could lead to coma (Adams, Brown, \& Turner, 2002).

Ethnomedically in South West Nigeria, many plants are used singly or in combination to treat malaria and anaemia. The bark of Anogeissus leiocarpus, a tree of up to $30 \mathrm{~m}$ in height with green foliage, is grey to beige in colour, becoming blackish with age and fibrous with thin scales (Bizimana, 1994). Traditionally, the inner bark of $A$. leiocarpus is used to treat many human and livestock diseases including trypanosomiasis, and babesiosis (Bizimana, 1994). The water extract of A. leiocarpus bark is used in Nigeria to treat malaria and anaemia. Akanbi, 
Omonkhua, Cyril-Olutayo and Fasimoye (2012) have demonstrated that the methanolic extract of $A$. leiocarpus bark has anti-malarial properties in $P$. berghei-infected mice. The stem bark of this plant contains castalagin and flavogallonic acid dilactone (Shuaibu et al., 2008). This study evaluated the effects of methanol extracts of $A$. leiocarpus bark as well as a standard antimalarial drug (artesunate) on the haematological status of mice infected with $P$. berghei.

\section{Methods}

\subsection{Parasites}

NK65 strain of $P$. berghei obtained from Department of Parasitology of the Nigerian Institute of Medical Research (NIMR), Akoka Yaba, Lagos State was sustained in the laboratory by passage of parasitized blood into mice.

\subsection{Laboratory Animals}

A total of twenty-five (25) adult Swiss albino mice, weighing between 18-25 g, obtained from the Animal Unit of the Obafemi Awolowo University (OAU), Ile-Ife, were used for this study. The animals were placed on standard pelleted feed and allowed to drink water freely. They acclimatized for two (2) weeks before the commencement of the study.

\subsection{Plant Preparation}

A. leiocarpus was collected from Akungba-Akoko, Ondo State, Nigeria and identified in the Department of Plant Science and Biotechnology, Adekunle Ajasin University, Akungba-Akoko. Herbarium specimen, with voucher number UIH22318 was deposited at the University of Ibadan Herbarium, Nigeria. The bark material was washed and dried under a shade; and then crushed into powder. Methanol was used to exhaustively extract $650 \mathrm{~g}$ of the powdered bark for three days. The filtered extract was concentrated in vacuo and serial dilutions made with distilled water to get the appropriate concentrations for oral administration to the mice.

\subsection{Experimental Design}

Twenty of the twenty five albino mice were inoculated by intra-peritoneal injection with $1 \times 10^{7}$ infected erythrocytes and parasitaemia was assessed from Geimsa stained thick blood films. The other 5 uninfected mice served as non-infected control (group A), 5 untreated $P$. berghei-infected mice served as negative control (group B), 5 artesunate-treated $(5 \mathrm{mg} / \mathrm{kg}$ body weight) $P$. berghei-infected mice served as positive control (group C), while 5 A. leiocarpus-treated (100 mg/kg body weight) P. berghei-infected mice and 5 A. leiocarpus $(200 \mathrm{mg} / \mathrm{kg}$ body weight) $P$. berghei-infected mice served as the medicinal plant treated groups (groups D and E). The various groups were fed and left for five days for parasitaemia establishment. The mice were treated for five days with the various drugs accordingly. Treatment of animals conformed to the guidelines of National Institute of Health publication 1985 for laboratory animal care and use.

\subsection{Blood Collection and Haematological Assays}

On the 5th day, the mice were sacrificed by stunning and blood was collected by heart puncture. Blood for haematological parameters was collected in EDTA bottles. These haematological parameters included red blood cell (RBC) count, white blood cell (WBC) count, platelet count, packed cell volume (PCV), haemoglobin (Hb) and differential leukocyte count were evaluated using standard methods.

\subsection{Statistical Analysis}

The significance of difference among groups was determined by the one-way analysis of variance (ANOVA), the Duncan's Test was used for Post Hoc analyses and $\mathrm{p}<0.05$ was accepted as significant. The SPSS 15.0, SPSS Inc., Chicago, Illinois, USA, was used for this analysis.

\section{Results}

The mean PCV was lower in negative control than in any other group as shown in Figure 1. The mean Hb levels were the same in all the treated animals, while its level was insignificantly lower in the negative control as compared to other groups (Figure 2). Figure 3 shows that the mean red blood cell level was higher in the group treated with $5 \mathrm{mg} / \mathrm{kg}$ body weight of artesunat than all other groups and it was lowest in negative control animals as compared with others. 


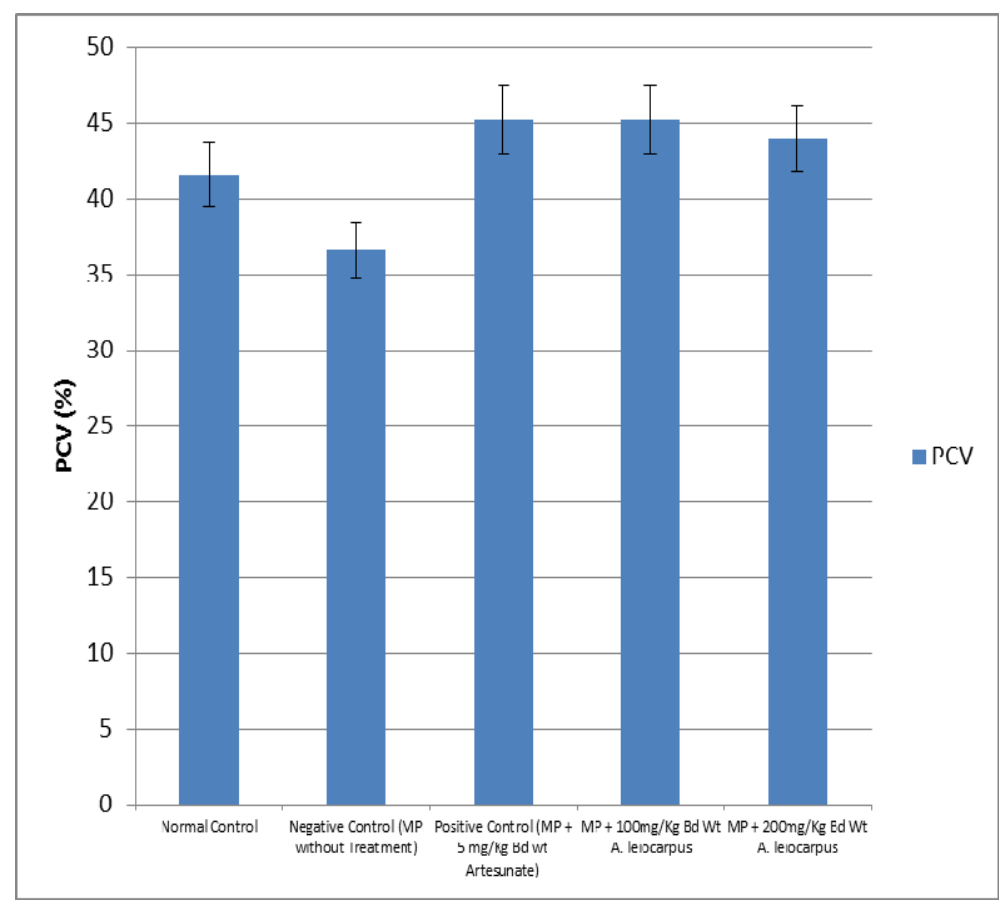

Figure 1. Effects of A. leiocarpus and artesunate on packed cell volume (PCV) of P. berghei-Infected Mice. Data are presented as means of 5 determinations \pm SEM

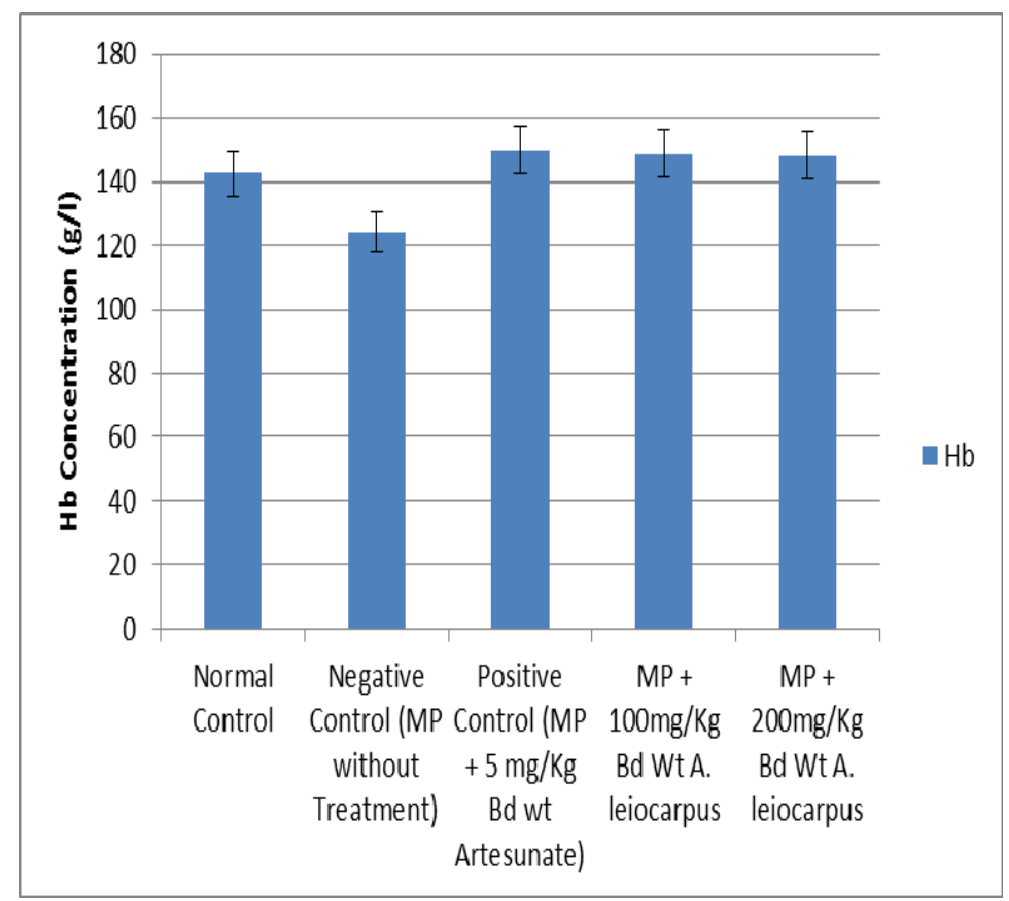

Figure 2. Effects of A. leiocarpus and artesunate on haemoglobin ( $\mathrm{Hb})$ concentration of $P$. berghei-Infected Mice. Data are presented as means of 5 determinations \pm SEM 


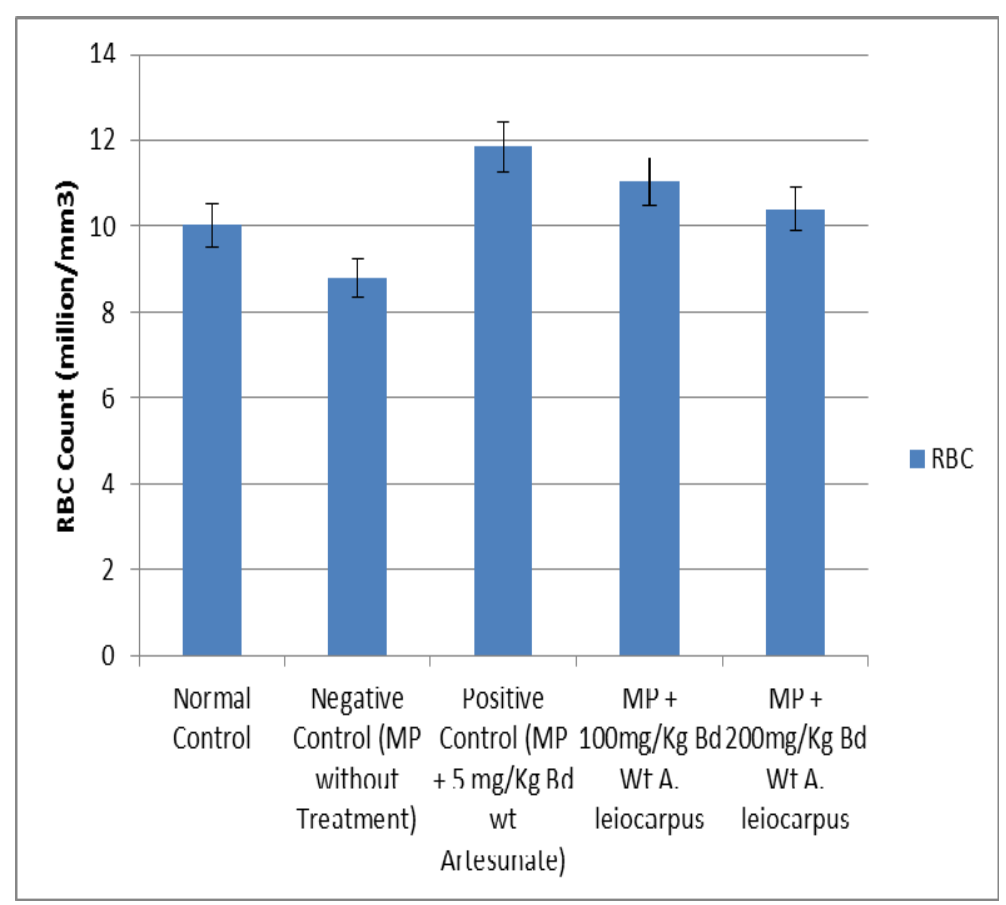

Figure 3. Effects of A. leiocarpus and artesunate on red blood cell (RBC) count of P. berghei-Infected Mice.

Data are presented as means of 5 determinations \pm SEM

All P. berghei infected mice had significantly $(\mathrm{p}<0.05)$ higher platelet count compared to normal control with the group treated with $200 \mathrm{mg} / \mathrm{kg}$ body weight of $A$. leiocarpus recording the highest value (Figure 4).

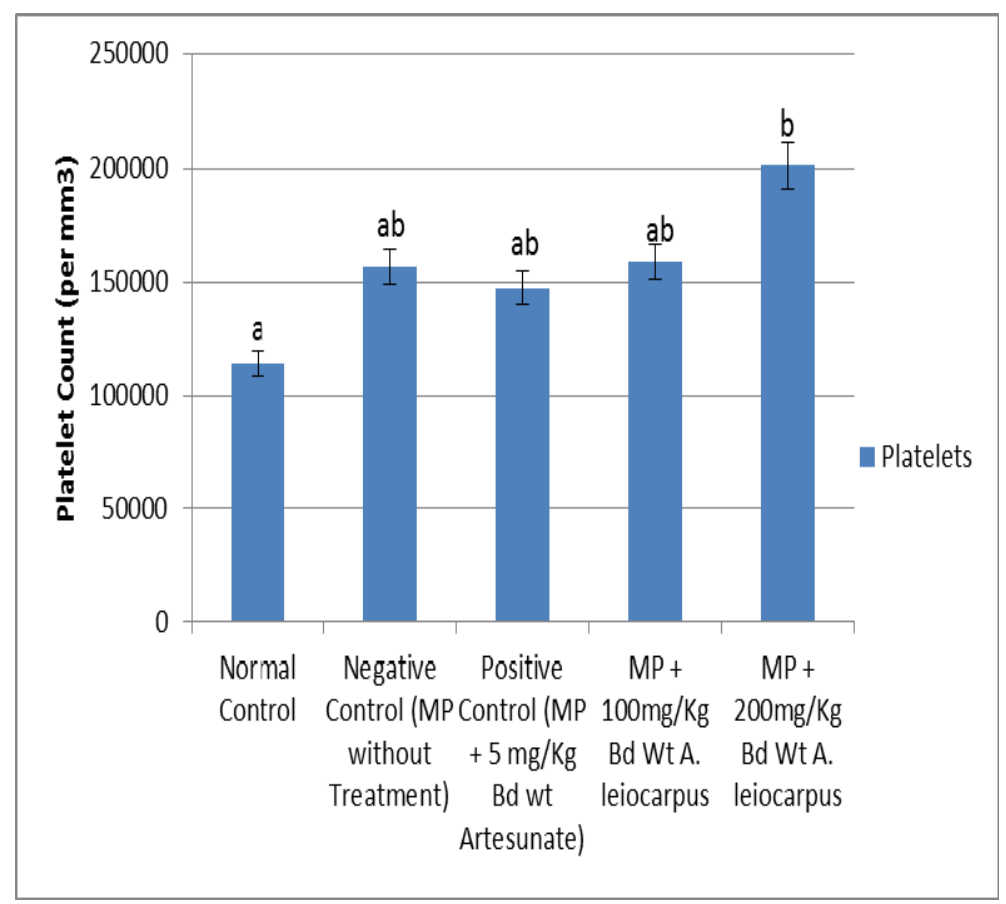

Figure 4. Effects of A. leiocarpus and artesunate on platelet count of $P$. berghei-Infected Mice. Data are presented as means of 5 determinations \pm SEM. Values with different notations are significant at $\mathrm{p}<0.05$ 
Though no statistically significant differences were observed among the groups, the artesunate and $A$. leiocarpus (100mg/kg body weight) treated infected mice, had lower WBC counts (Figure 5).

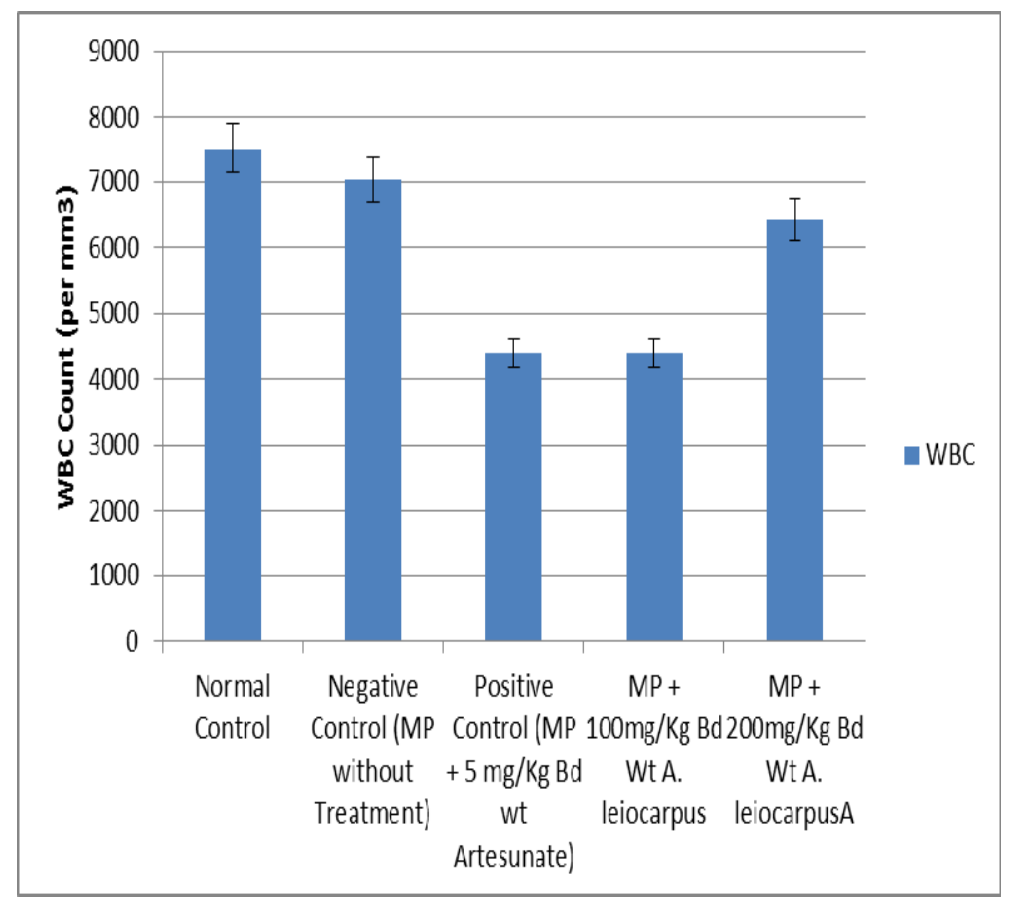

Figure 5. Effects of A. leiocarpus and artesunate on white blood cell (WBC) count of P. berghei-Infected Mice. Data are presented as means of 5 determinations \pm SEM

The mean neutrophil count was significantly higher $(\mathrm{p}<0.05)$ in negative control compared to normal control and treated infected groups (Figure 6).

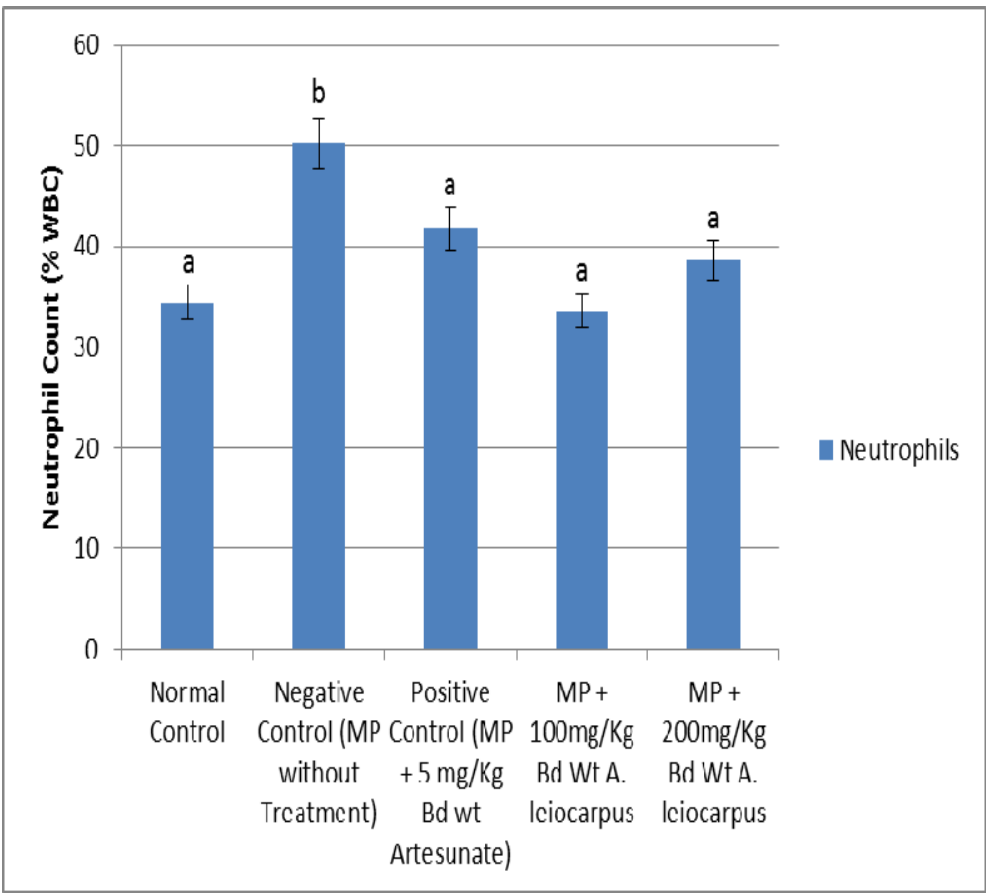

Figure 6. Effects of A. leiocarpus and artesunate on neutrophil count of $P$. berghei-Infected Mice. Data are presented as means of 5 determinations \pm SEM. Values with different notations are significant at $\mathrm{p}<0.05$ 
The untreated $P$. berghei infected mice recorded a significantly $(\mathrm{p}<0.05)$ lower lymphocyte count compared with normal control and treated infected mice (Figure 7).

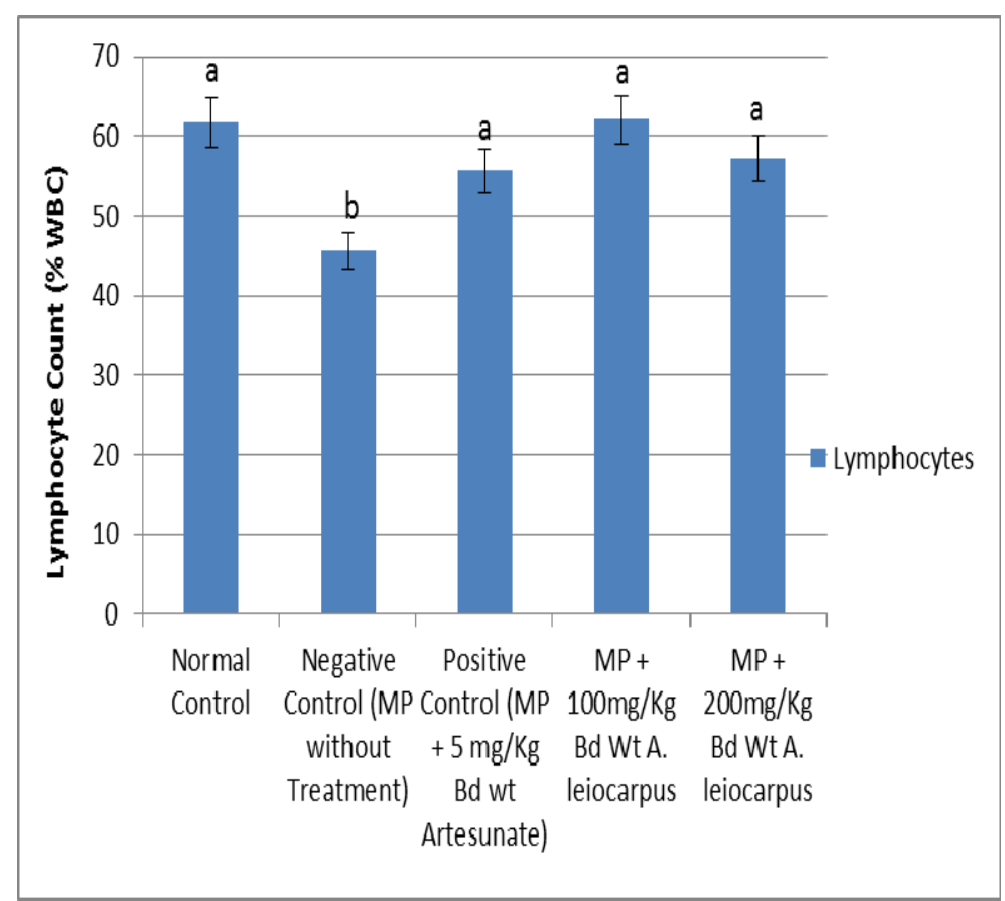

Figure 7. Effects of A. leiocarpus and artesunate on lymphocyte count of P. berghei-Infected Mice. Data are presented as means of 5 determinations \pm SEM. Values with different notations are significant at $p<0.05$

All P. berghei infected groups had monocyte counts lower than normal control. Artesunate and A. leiocarpus $(100 \mathrm{mg} / \mathrm{kg}$ body weight) groups had the lowest values (Figure 8 ).

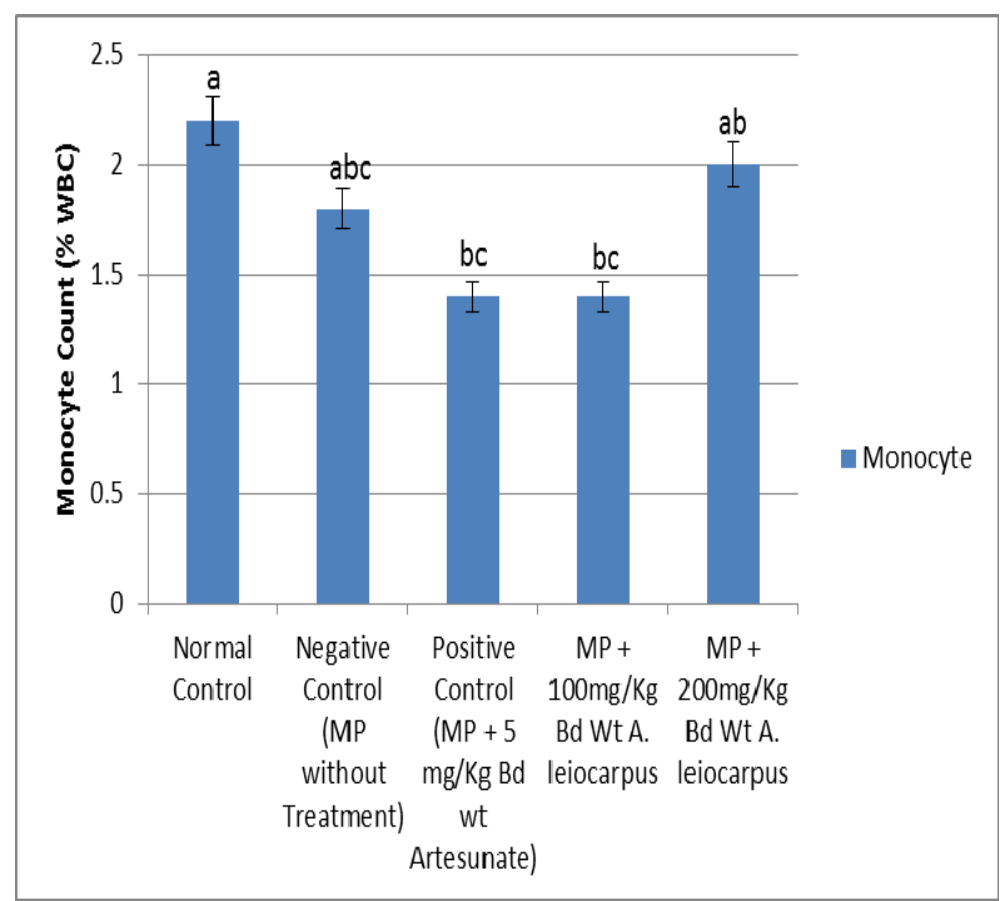

Figure 8. Effects of A. leiocarpus and artesunate on monocyte count of $P$. berghei-Infected Mice. Data are presented as means of 5 determinations \pm SEM. Values with different notations are significant at $\mathrm{p}<0.05$ 
All $P$. berghei infected mice had higher eosinophil counts compared to normal control. Artesunate and $A$. leiocarpus $(100 \mathrm{mg} / \mathrm{kg}$ body weight) groups had the highest values while A. leiocarpus ( $100 \mathrm{mg} / \mathrm{kg}$ body weight) group had the lowest (Figure 9).

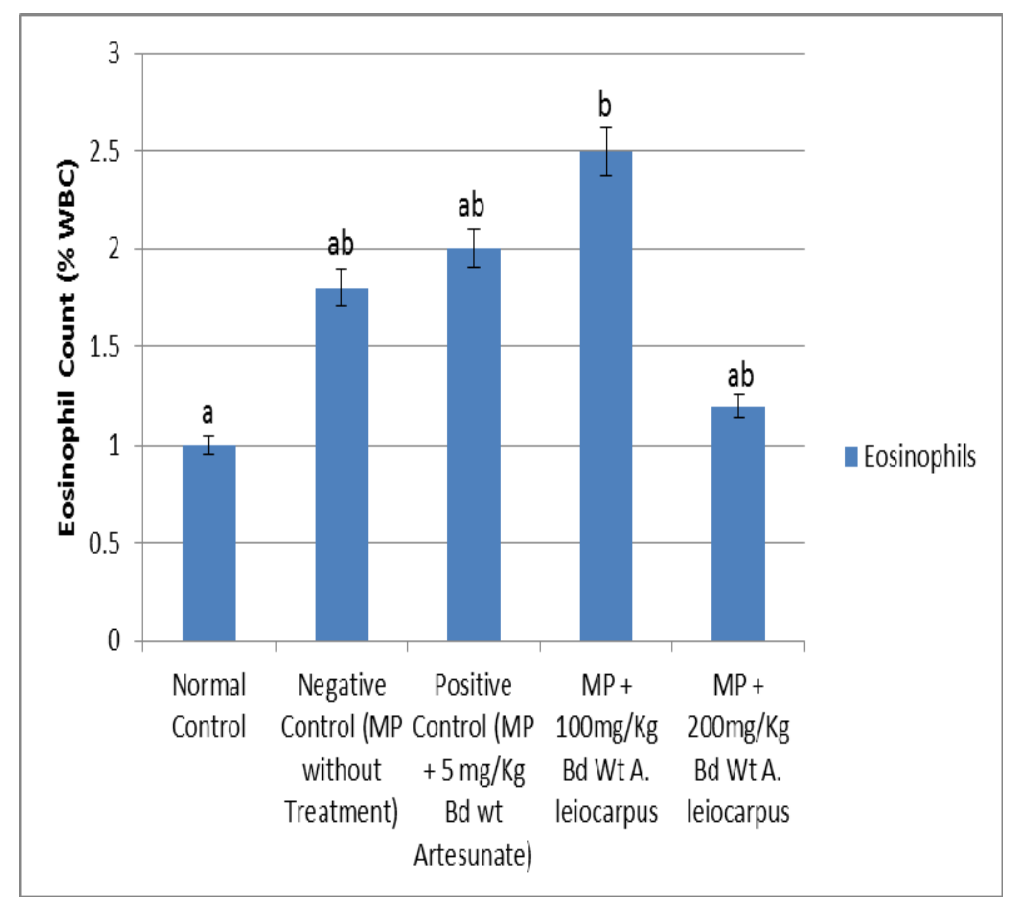

Figure 9. Effects of A. leiocarpus and artesunate on eosinophil count of $P$. berghei-Infected Mice. Data are presented as means of 5 determinations \pm SEM. Values with different notations are significant at $\mathrm{p}<0.05$

Though no significant difference was recorded in the basophil count among groups, the untreated infected mice (negative control group) had the lowest values (Figure 10).

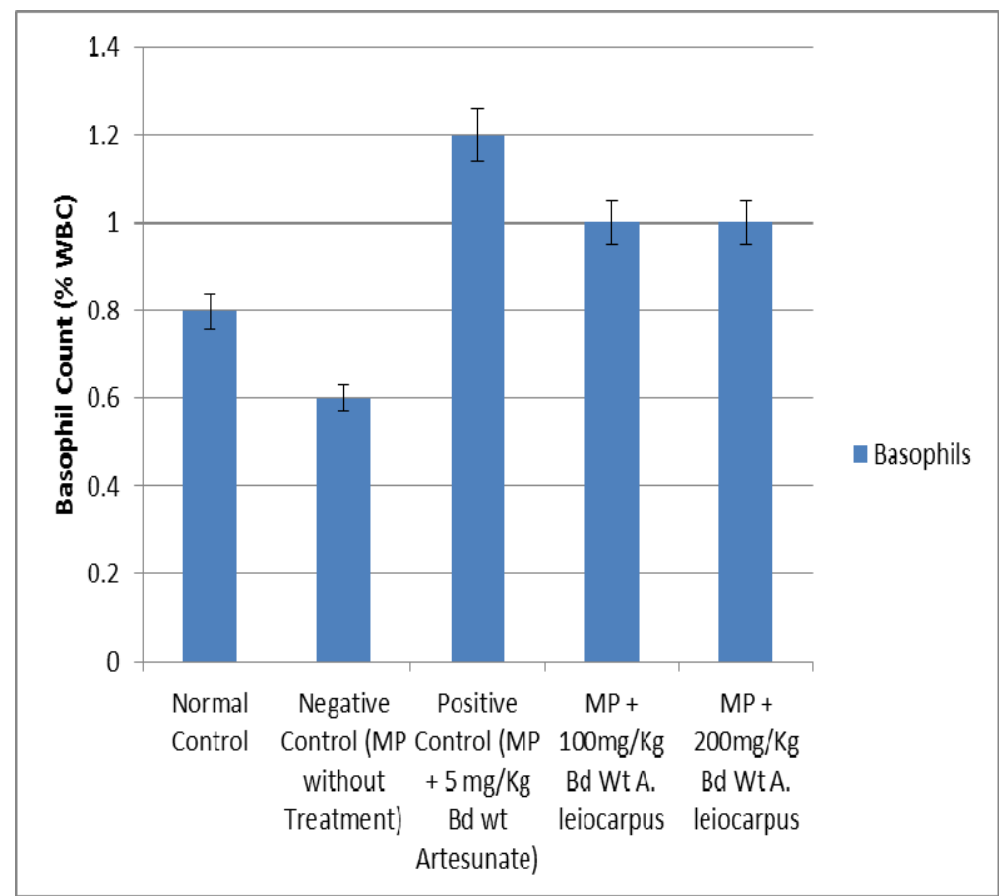

Figure 10. Effects of A. leiocarpus and artesunate on basophil count of $P$. berghei-Infected Mice. Data are presented as means of 5 determinations \pm SEM. Values with different notations are significant at $\mathrm{p}<0.05$ 


\section{Discussion}

Evaluating the complete blood count provides enormous information on the haematological status in disease conditions (Lathia \& Joshi, 2004). Anaemia is usually assessed by evaluating packed cell volume, haemoglobin and red blood cell count. It can clearly be seen that the untreated P. berghei infected mice (negative control) had the lowest values for these parameters. This is consistent with the anaemia seen in malaria. An unusually low haemoglobin concentration is implicative of anaemia. This may result from a reduction in erythrocyte number or a reduction in the concentration of haemoglobin in each erythrocyte (Lathia \& Joshi, 2004). Treatment with artesunate and A. leiocarpus extract however raised the values of these parameters to control or higher than control levels, implying that the extract of this plant has anti-anaemic properties. Lathia and Joshi (2004) reported that reduced haemoglobin and platelet count increase the probability of malaria by factors of 1.95 and 5.04 respectively. The slight increase in platelet count seen in all P. berghei infected mice in this study may be as a result of the short period of infection; it is possible that prolonged or repeated infections may lead to thrombocytopenia. White blood cells (WBCs), as well as other cells, are involved in the body's immune system and help to fight diseases. They are increased in normal situations such as exertion and pregnancy, and abnormally in situations such as loss of blood, cancer, and most infections. Though increase in WBCs have been demonstrated to be linked to severe malaria (Modiano, Sirima, Konate, Sanou, \& Sawadogo, 2001), during acute malaria WBC counts are generally observed to be low or normal (White \& Breman, 2001). Our results show that WBC counts for all groups were not statistically altered; however, artesunate and $100 \mathrm{mg} / \mathrm{kg}$ body weight of $A$. leiocarpus slightly reduced WBC count (Figure 5). A WBC differential count examines the amount of each of the five different types of leukocytes. A high neutrophil count usually implies an infection while a reduced lymphocyte count may indicate a compromised immune system or if the case of increased neutrophils, imply an infection (Jaeger \& Hedegaard, 2002). P. berghei infection significantly $(\mathrm{p}<0.05)$ altered neutrophil and lymphocyte counts, whereas treatment with artesunate and A. leiocarpus at 100 and $200 \mathrm{mg} / \mathrm{ml}$ body weight brought the levels of these parameters to control values (Figures 6 and 7). The monocyte, eosinophil and basophil counts for the $P$. berghei infected mice were not significantly altered by the different forms of treatment; a longer period of time may be required for more profound changes to be seen in these parameters.

\section{Conclusion}

The use of the bark methanolic extract of Anogeissus leiocarpus both at $100 \mathrm{mg}$ and $200 \mathrm{mg} / \mathrm{kg}$ body weight compares significantly with the use of artesunate (positive control) in the treatment of Plasmodium infection and the effects on haematological parameters associated with the presence of $P$. bergei in the blood. Hence $A$. leiocarpus has been established in this work to have anti-anaemic properties and the white blood differential count indicates a boost in the immune system of the treated $P$. berghei infected mice. These findings therefore confirm the ethnomedicinal use of the bark extract of $A$. leiocarpus for treating malaria related anaemia.

\section{Acknowledgements}

We wish to acknowledge the Adekunle Ajasin University Health Centre, Akungba-Akoko, for the haematological analysis.

\section{References}

Adams, S., Brown, H., \& Turner, G. (2002). Breaking down the blood-brain barrier: signaling a path to cerebral malaria? Trends in Parasitology, 18(8), 360-366. http://dx.doi.org/10.1016/S1471-4922(02)02353-X

Akanbi, O. M., Omonkhua, A. A., Cyril-Olutayo, C. M., \& Fasimoye, R. Y. (2012). The antiplasmodial activity of Anogeissus leiocarpus and its effect on oxidative stress and lipid profile in mice infected with Plasmodium bergheii. Parasitology Research, 110(1), 219-226. http://dx.doi.org/10.1007/s00436-011-2472-7

Bizimana, N. (1994). Traditional Veterinary Practice in Africa. German Technical Cooperation.

Chen, Q., Schlichtherle, M., \& Wahlgren, M. (2000). Molecular aspects of severe malaria. Clinical Microbiology Review, 1(3), 439-450. http://dx.doi.org/10.1128/CMR.13.3.439-450.2000

Fleming, A. F. (1981). Hematological manifestations of malaria and other parasitic diseases. Clinical Haematology, 10, 983-1011. Retrieved from http://www.ncbi.nlm.nih.gov/pubmed/7030561?dopt=Abstract

Jaeger, J. J., \& Hedegaard, H. (2002). Liver function tests and blood tests: In the Danish Hepatitis C website. Retrieved from http://home3 .inet.tele.dk/omni/ alttest.html.

Lamikanra, A. A., Brown, D., \& Potocnik, A. (2007). Malarial anemia: of mice and men. Blood, 110, 18. http://dx.doi.org/10.1182/blood-2006-09-018069 
Lathia, T. B., \& Joshi, R. (2004). Can hematological parameters discriminate malaria from nonmalarious acute febrile illness in the tropics? Indian Journal of Medical Sciences, 58, 239-244.

Menendez, C., Fleming, A. F., \& Alonso, P. L. (2000). Malaria-related anaemia. Parasitology Today, 16(11), 469-476. http://dx.doi.org/10.1016/S0169-4758(00)01774-9

Modiano, D., Sirima, B. S., Konate, A., Sano, I., \& Sawadogo, A. (2001). Leucocytosis in severe malaria. Transactions of the Royal Society of Tropical Medidicne and Hygiene, 95(2), 175-176. http://dx.doi.org/10.1016/S0035-9203(01)90152-X

Shuaibu, M. N., Pandey, K., Wuyep, P. A., Yanagi, T., Hirayama, K., Ichinose, A., ... Kouno, I. (2008). Castalagin from Anogeissus leiocarpus mediates the killing of Leishmania in vitro. Parasitology Research, 103(6), 1333-1338. http://dx.doi.org/10.1007/s00436-008-1137-7

Snow, R. W., Guerra, C. A., Noor, A. M., Myint, H. Y., \& Hay, S. I. (2005). The global distribution of clinical episodes of Plasmodium falciparum malaria. Nature, 434(7030), 214-217. http://dx.doi.org/10.1038/nature03342

White, N. J., \& Breman, J. G. (2001). Malaria and Babesiosis: Diseases caused by red blood cell parasites. In Eugene Braunwald (Ed.), Harrison's Principles of Internal Medicine (pp. 1203-1212). New York: Mcgraw-Hill. 